\title{
Influência do uso de aditivo retentor de água à base de éter de celulose nas propriedades das argamassas de assentamento em alvenaria estrutural de blocos de concreto
}

\author{
Influence of water-retaining cellulose ethers on the \\ properties of bedding mortar used in concrete structural \\ masonry
}

\author{
Alexandre Lima Oliveira \\ Bruna Petter Corrêa \\ Igor Fernando Reitz Ribeiro \\ Rafael Andrade Souza \\ Luciana Maltes Lengler Calçada
}

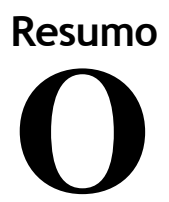
argamassa mista de cimento e cal, em diferentes teores $(0,00 \%, 0,03 \%, 0,06 \%$ e $0,09 \%$ em relação à massa total de materiais secos) para a avaliação da influência do referido aditivo nas propriedades das argamassas no estado fresco e endurecido. Além disso, foram confeccionados prismas com três blocos e miniprismas, com pedaços serrados de blocos, para avaliação da resistência à compressão, módulo de deformação e tensão de aderência. Os resultados mostraram que existe potencial para se empregarem retentores de água à base de éter de celulose para a confecção de argamassas de assentamento para alvenaria estrutural de blocos de concreto, haja vista que houve aumento da capacidade de retenção de água das argamassas e que o uso do referido produto não exerceu influência na resistência à compressão delas e na resistência à compressão dos prismas. Contudo, a resistência à compressão das juntas de assentamento, o módulo de elasticidade dos prismas e a resistência à aderência na flexão sofreram reduções significativas quando do emprego do éter de celulose.

Alexandre Lima Oliveira Instituto Federal de Santa Catarina Florianópolis - SC - Brasil

Bruna Petter Corrêa Schveper Instituto Federal de Santa Catarina Florianópolis - SC - Brasil

Igor Fernando Reitz Ribeiro Instituto Federal de Santa Catarina Florianópolis - SC - Brasil

Rafael Andrade Souza Instituto Federal de Santa Catarina Florianópolis - SC - Brasil

Luciana Maltes Lengler Calçada Instituto Federal de Santa Catarina Florianópolis - SC - Brasil

Recebido em 24/08/14 Aceito em 08/04/15
Palavras-chaves: Retentor de água. Éter de celulose. Argamassa de assentamento. Alvenaria estrutural. Blocos de concreto.

\section{Abstract}

The aim of this study was to investigate the influence of water-retaining cellulose ethers agent on the bedding mortar in concrete structural masonry.

Hydroxypropylmethyl cellulose (HPMC) was used in different proportions in a cement-lime based mortar $(0.00 \%, 0.03 \%, 0.06 \%$ and $0.09 \%$ of the total dry weight) to evaluate the influence of cellulose ethers on the properties of mortars in the fresh and hardened states. In addition, prisms were produced from three concrete blocks and mini-prisms were sawed off concrete blocks to evaluate that there is potential in the use of water-retaining cellulose ethers agent in the bedding mortar of concrete structural masonry, since that there was an increase in the water retention capacity of the mortars and the use of these products did not influence the compressive strength of the mortar and the masonry prisms. However the compressive strength of the bedding mortar joints, the modulus of elasticity of the prisms and the bond strength in flexion were significantly reduced, when cellulose ether was used.

Keywords: Water-retaining agent. Cellulose ethers. Bedding mortar. Structural masonry. Concrete blocks. compressive strength, modulus of elasticity and bond strength. The results showed

OLIVEIRA, A. L.; CORRÊA, B. P.; RIBEIRO, I. F. R.; SOUZA, R. A.; CALÇADA; L. M. L. Influência do uso de aditivo retentor de água à base de éter de celulose nas propriedades das argamassas de assentamento em alvenaria estrutural de blocos de concreto. Ambiente Construído, Porto Alegre,v. 15, n. 3, p. 57-59, jul./set. 2015. ISSN 1678-8621 Associação Nacional de Tecnologia do Ambiente Construído. http://dx.doi.org/10.1590/s1678-86212015000300026 


\section{Introdução}

As propriedades das juntas de assentamento de uma alvenaria estrutural de blocos de concreto e o desempenho do conjunto (parede de alvenaria) dependem em grande parte das propriedades das argamassas de assentamento, tanto no estado fresco como no estado endurecido (STEIL, 2003; CASALI, 2008; SCHANKOSKI, 2012).

No momento em que a argamassa é colocada em contato com o bloco, inicia-se um processo de remoção de água e adensamento da junta, que dependem das propriedades do bloco e da argamassa que estão sendo empregados. Essa transferência de água da junta de assentamento para o bloco pode causar maior densificação da junta, diminuindo os vazios e resultando em aumento da resistência à compressão; ou causar dessecação da junta (perda de água excessiva), o que pode acarretar uma matriz com alto teor de vazios e baixa resistência à compressão (CASALI, 2008). Essa questão de densificação ou dessecação está intimamente ligada à porosidade e absorção do bloco, bem como à capacidade de retenção de água da argamassa.

O emprego de aditivos retentores de água tem sido uma das soluções utilizadas pela indústria de argamassa pré-fabricada para aumentar a capacidade de retenção de água das argamassas de revestimento e de assentamento. Também conhecidos como aditivos promotores de viscosidade, os aditivos retentores de água são em sua maioria à base de éter de celulose, sendo os mais comumente empregados na confecção de argamassas o hidroxipropil-metilcelulose (HPMC) e o hidroxietil-metilcelulose (HEMC) (PAIVA et al., 2006).

Polímeros à base de éter de celulose são materiais orgânicos derivados da celulose e solúveis em água, que apresentam como propriedade principal a grande capacidade de reter água (PAIVA et al., 2009).

Além disso, aumentam a coesão e promovem melhoras na trabalhabilidade e no processo de hidratação do cimento (PAIVA et al., 2009; AFRIDI et al., 1995; KNAPEN; GEMERT, 2009).

No entanto, como efeito secundário, os produtos à base de éter de celulose podem alterar o tempo de início de pega do cimento, reduzir a consistência das argamassas e causar excessiva incorporação de ar nelas (KNAPEN; GEMERT, 2009; JENNI et al., 2005, 2006).

Atualmente existem no mercado brasileiro inúmeras argamassas desenvolvidas para a confecção de alvenaria estrutural contendo polímeros à base de éter de celulose. Entretanto, trabalhos como o de Steil (2003), Casali (2008) e Schankoski (2012) mostraram que esses tipos de argamassas podem em alguns casos comprometer o fator de eficiência dos prismas de alvenaria, reduzir o módulo de deformação dos prismas (o que em alguns casos é um fator positivo), alterar o mecanismo de ruptura dos prismas de alvenaria e prejudicar significativamente a tensão de aderência. Existem relatos de edifícios construídos no oeste de Santa Catarina (CASALI, 2008) onde argamassas com esse tipo de polímero causaram fissuras patológicas em diversos andares, em virtude da baixíssima tensão de aderência bloco/junta.

Nesse contexto, o presente trabalho teve como objetivo principal verificar a influência do emprego de diferentes teores de um aditivo retentor de água à base de éter de celulose nas propriedades das argamassas, tanto no estado fresco como no endurecido, bem como verificar o desempenho delas em prismas e miniprismas de alvenaria, para avaliação de sua capacidade portante (resistência à compressão), módulo de deformação e tensão de aderência na flexão.

\section{Programa experimental}

Para a realização do presente trabalho foi proposto um programa experimental, dividido em duas fases:

(a) fase 1: avaliação da influência do aditivo à base de éter de celulose nas propriedades das argamassas: nesta fase do trabalho foram feitos testes em argamassas, incorporando-se diferentes teores de éter de celulose, para verificar a influência deste nas propriedades das argamassas no estado fresco (consistência, teor de ar incorporado e retenção de água), bem como no estado endurecido (resistência à compressão); e

(b) fase 2: avaliação do desempenho das argamassas em blocos de concreto: com base nos resultados obtidos na primeira fase do estudo, foram selecionadas algumas das argamassas para avaliação de seu desempenho em conjunto com blocos de concreto para alvenaria estrutural. Para tal foram moldados prismas de alvenaria (prismas de 3 blocos) para avaliação do desempenho à compressão, bem como miniprismas, conforme proposto por Casali (2008), para avaliação da tensão de aderência. 


\section{Materiais empregados}

Para a confecção das argamassas foram empregados cimento CPII-F 32 e cal hidratada $\mathrm{CH}$ III, juntamente com um agregado miúdo natural de rio, proveniente da região da Grande Florianópolis. Nas Tabelas 1, 2 e 3 são apresentadas respectivamente as caracterizações do cimento, da cal e do agregado miúdo empregados no presente estudo.

Tabela 1 - Características físicas, químicas e mecânicas do cimento CPII-F 32

\begin{tabular}{|c|c|c|c|c|c|}
\hline & Item de controle & Média & Desvio & Mínimo & Máximo \\
\hline \multirow{12}{*}{ 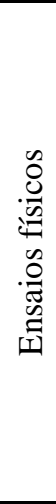 } & Material retido \#200 (mesh) (\%) & 4,67 & 0,61 & 3,70 & 5,80 \\
\hline & Material retido \#325 (mesh) (\%) & 16,41 & 1,89 & 12,80 & 19,90 \\
\hline & Blaine $\left(\mathrm{cm}^{2} / \mathrm{g}\right)$ & 3267 & 192,96 & 2990 & 3570 \\
\hline & Água de consistência (\%) & 24,9 & 0,3 & 24,4 & 25,5 \\
\hline & Início de pega (horas) & 03:07 & $00: 14$ & 03:30 & 04:15 \\
\hline & Fim de pega (horas) & 03:53 & $00: 14$ & 03:30 & 04:15 \\
\hline & Expansibilidade a quente (mm) & 0,76 & 0,26 & 0,50 & 1,00 \\
\hline & Resistência a 1 dia (MPa) & 11,1 & 1,0 & 9,8 & 12,8 \\
\hline & Resistência aos 3 dias (MPa) & 24,8 & 0,9 & 23,1 & 26,5 \\
\hline & Resistência aos 7 dias (MPa) & 31,7 & 0,9 & 30,4 & 33,4 \\
\hline & Resistência aos 28 dias (MPa) & 40,1 & 0,9 & 38,4 & 41,7 \\
\hline & Massa específica $\left(\mathrm{g} / \mathrm{cm}^{3}\right)$ & 3,09 & - & - & - \\
\hline \multirow{9}{*}{ 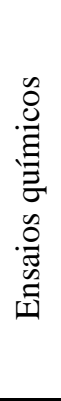 } & Perda ao fogo (\%) & 5,31 & 0,20 & 5,08 & 5,81 \\
\hline & $\mathrm{SiO}_{2}(\%)$ & 18,63 & 0,07 & 18,45 & 18,73 \\
\hline & $\mathrm{AL}_{2} \mathrm{O}_{3}(\%)$ & 4,12 & 0,01 & 4,10 & 4,15 \\
\hline & $\mathrm{Fe}_{2} \mathrm{O}_{3}(\%)$ & 2,58 & 0,01 & 2,57 & 2,60 \\
\hline & $\mathrm{CaO}(\%)$ & 59,90 & 0,07 & 59,71 & 59,98 \\
\hline & $\mathrm{MgO}(\%)$ & 4,62 & 0,23 & 4,15 & 4,92 \\
\hline & Equivalente alcalino (\%) & 0,60 & 0,01 & 0,59 & 0,61 \\
\hline & $\mathrm{SO}_{3}(\%)$ & 3,05 & 0,06 & 2,93 & 3,18 \\
\hline & Resíduo insolúvel (\%) & 1,11 & 0,17 & 0,90 & 1,40 \\
\hline
\end{tabular}

Tabela 2 - Caracterização da cal hidratada CH III

\begin{tabular}{cc}
\hline Ensaio & Teor (\%) \\
\hline $\mathrm{CaO}$ & 38,00 \\
$\mathrm{MgO}$ & 24,50 \\
Perda ao fogo & 25,55 \\
Resíduo insolúvel & 7,84 \\
Massa unitária $\left(\mathrm{g} / \mathrm{cm}^{3}\right)$ & 0,62 \\
Massa específica $\left(\mathrm{g} / \mathrm{cm}^{3}\right)$ & 2,42 \\
\hline
\end{tabular}

Tabela 3 - Caracterização do agregado miúdo natural

\begin{tabular}{cc}
\hline Abertura das peneiras (mm) & $\begin{array}{c}\text { Porcentagem } \\
\text { retida } \\
\text { acumulada }\end{array}$ \\
\hline 4,8 & 0 \\
2,40 & 3 \\
1,20 & 27 \\
0,60 & 52 \\
0,30 & 76 \\
0,15 & 93 \\
Fundo & 100 \\
Módulo de finura & 2,51 \\
Material pulverulento $(\%)$ & 4,0 \\
Massa específica (kg/dm $\left.{ }^{3}\right)$ & 2,58 \\
\hline
\end{tabular}


Neste trabalho foi empregado um aditivo hidroxipropil-metilcelulose (HPMC) em pó, cujas propriedades principais encontram-se apresentadas na Tabela 4. Vale ressaltar que em função de possíveis efeitos secundários de incorporação excessiva de ar empregou-se em algumas argamassas, juntamente com o HPMC, um aditivo desincorporador de ar (líquido).

Na Fase 2 do presente trabalho foram empregados blocos de concreto estruturais de $14 \times 19 \times 39 \mathrm{~cm}$ (largura $\mathrm{x}$ altura $\mathrm{x}$ comprimento) de um fabricante da Grande Florianópolis, comercializados como blocos classe $\mathrm{A}$, com resistência à compressão característica igual a $6,0 \mathrm{MPa}$ segundo a NBR 6136 (ABNT, 2007). Na Figura 1 e na Tabela 5 são apresentadas respectivamente as dimensões e propriedades dos blocos de concretos empregados na segunda fase do presente trabalho.

\section{Avaliação da influência do aditivo à base de éter de celulose nas propriedades das argamassas (Fase 1)}

Foi empregada uma argamassa de referência nas proporções 1:0,5:6,0:1,55 (cimento: cal: areia: água) em massa. Tomando-se essa argamassa como base, foram adicionados diferentes teores de HPMC, conforme valores apresentados na Tabela 6. Além disso, foram produzidas algumas argamassas contendo HPMC juntamente com um aditivo desincorporador de ar, conforme mencionado anteriormente.

Tabela 4 - Propriedades do hidroxipropil-metilcelulose (HPMC)

\begin{tabular}{cc}
\hline Propriedade & Resultado \\
\hline Massa molecular $(\mathrm{g} / \mathrm{mol})$ & 955.000 \\
Quantidade do grupo $\mathrm{O}-\mathrm{CH}_{3}$ & $27,5 \%$ \\
Quantidade do grupo POOH & 10,65 \\
\hline
\end{tabular}

Tabela 5 - Propriedades dos blocos de concreto empregados neste trabalho (Fase 2)

\begin{tabular}{c|c|c|c}
\hline Propriedades & Média & sd & CV (\%) \\
\hline Resistência à compressão (MPa) & 8,38 & 1,04 & 12,46 \\
\hline Absorção de água & $6,03 \%$ & $0,30 \%$ & 5,06 \\
\hline $\begin{array}{c}\text { Absorção de água por capilaridade } \\
\text { (menor área - base) (g/cm²/min) }\end{array}$ & 0,19 & 7,47 & 0,13 \\
\hline $\begin{array}{c}\text { Absorção de água por capilaridade } \\
\text { (maior área - topo) (g/cm²/min) }\end{array}$ & 0,11 & 10,42 & 0,31 \\
\hline Resistência característica (fbk) & \multicolumn{3}{|c}{$6,65^{1}(6,00)^{2}$} \\
\hline
\end{tabular}

Nota: 1 - Resistência característica determinada segundo a NBR 6136 (ABNT, 2007); e 2 - Valor indicado entre parênteses: resistência característica indicada pelo fabricante.

Figura 1 - Geometria do bloco de concreto empregado na segunda fase do programa experimental (dimensões em milímetros)
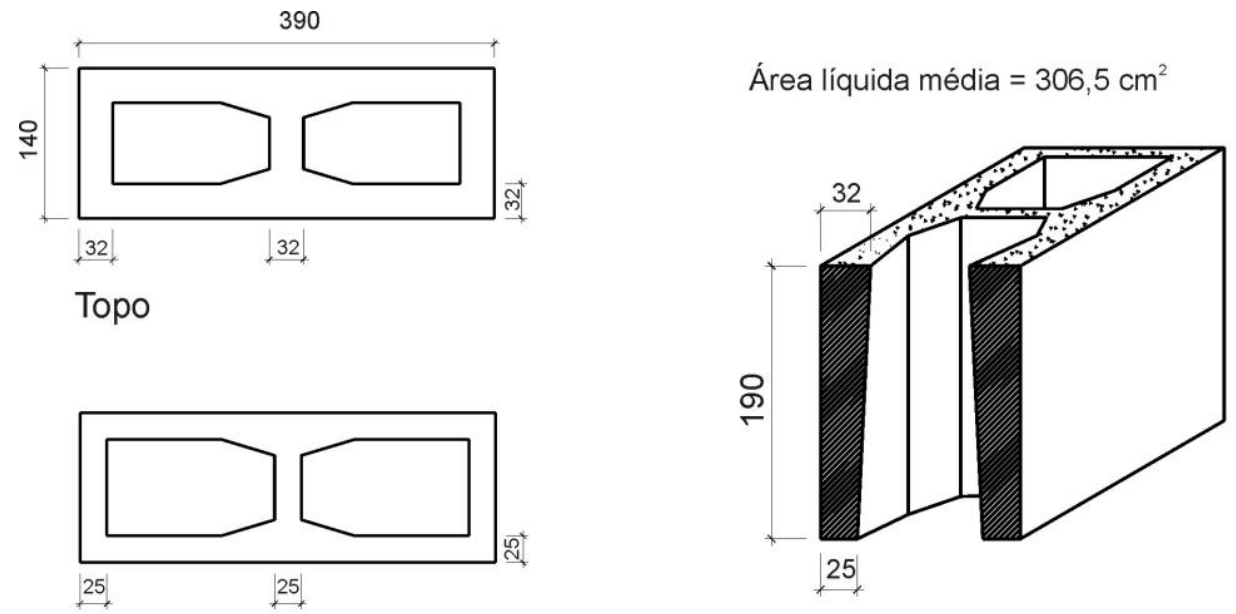

Base

60 Oliveira, A. L.; Corrêa, B. P.; Ribeiro, I. F. R.; Souza, R. A.; Calçada; L. M. L. 
Ao término do processo de mistura foram determinados o índice de consistência das argamassas, tomando-se como base as preconizações da NBR 13276 (ABNT, 2005a); o teor de ar incorporado, segundo a NBR 13278 (ABNT, 2005b); e a retenção de água delas com base na ASTM C91 (AMERICAN..., 2003).

Além dos ensaios de caracterização no estado fresco, foram moldados 3 corpos de prova cilíndricos $-5 \times 10 \mathrm{~cm}$ (diâmetro x altura) -, para avaliação da resistência à compressão aos 28 dias. Os corpos de prova foram desmoldados com $48 \mathrm{~h}$ e curados ao ar até a data de ensaio.

\section{Avaliação do desempenho das argamassas em blocos de concreto (Fase 2)}

O objetivo principal dessa fase do trabalho foi avaliar o desempenho das argamassas com aditivo HPMC, ante uma argamassa de referência com bom histórico em trabalhos anteriores, quando sujeitas à compressão em prismas de alvenaria, bem como a tensão de aderência na flexão, empregando-se o procedimento proposto por Casali (2008) - ensaio de flexão de quatro pontos em miniprismas. Além disso, foram determinadas as resistências das juntas de assentamento empregando-se o ensaio de cravação pneumática de pinos proposto por Oliveira et al. (2012), para avaliação do efeito do HPMC nas juntas de assentamento.

Nesta fase do trabalho foram confeccionadas novamente as argamassas que apresentaram bom desempenho na Fase 1 e foram empregados os blocos de concreto descritos anteriormente na Fase 1. A seleção dos blocos foi feita com base no peso deles, na tentativa de minimizar as variações de resistência à compressão e uma possível influência nos resultados de rompimento dos prismas de alvenaria. Todos os blocos selecionados apresentavam pesos entre $13.300 \mathrm{~g}$ e $13.500 \mathrm{~g}$, evitando-se coletar blocos com defeitos visíveis.

Foram confeccionados prismas de alvenaria de 3 blocos (3 prismas para cada argamassa - Figura 2a) e miniprismas (6 miniprismas para cada argamassa - Figura 2b). Para a confecção dos miniprismas foram serrados pedaços de blocos e assentados conforme detalhe apresentado na Figura 3, empregando-se uma base suporte (Figura 2b).

Em paralelo à moldagem dos prismas e miniprismas foram moldados 6 corpos de prova cilíndricos $(5 \mathrm{~cm} \times 10 \mathrm{~cm})$ para a determinação da resistência à compressão e do módulo de deformação das argamassas confeccionadas nesta etapa do trabalho.

Tanto os prismas de 3 blocos (ensaio à compressão) como os miniprismas (ensaio à flexão) foram curados ao ar, em laboratório, por um período de 28 dias, quando então foram submetidos ao carregamento. Vale destacar que os blocos de topo e base dos prismas de 3 blocos foram previamente capeados com pasta de cimento para minimizar eventuais efeitos de concentração de carga. Os miniprismas foram capeados com pasta de gesso dois dias antes do ensaio para melhorar o contato com as bases de apoio.

Antes da aplicação de carga nos prismas de alvenaria foram feitos ensaios de cravação pneumática de pinos para a estimativa da resistência à compressão das juntas de alvenaria (Figura 4a). Após a leitura das profundidades de cravação obtidas nas juntas superiores e inferiores foram instalados dispositivos de fixação para relógios comparadores analógicos com precisão de milésimo de milímetro (Figura 4b) para a determinação do módulo de deformação dos prismas.

Tabela 6 - Argamassas produzidas na primeira fase do trabalho

\begin{tabular}{ccc}
\hline Argamassa & $\begin{array}{c}\text { Aditivo } \\
\text { desincorporador }^{2}\end{array}$ & HPMC $^{\mathbf{3}}$ \\
\hline REF $^{1}$ & - & - \\
R-3 & - & $0,03 \%$ \\
R-6 & - & $0,06 \%$ \\
R-9 & - & $0,09 \%$ \\
RD-3 & $2,0 \%$ & $0,03 \%$ \\
RD-6 & $2,0 \%$ & $0,06 \%$ \\
RD-9 & $2,0 \%$ & $0,09 \%$ \\
\hline
\end{tabular}

Nota: 1 - Argamassa de referência (sem emprego de aditivos); 2 - Teor de aditivo desincorporador de ar em relação à massa de cimento; e 3 - Teor de aditivo retentor de água em relação à massa total de materiais secos. Esses teores de HPMC foram definidos em estudos pilotos, em que teores acima de 0,10\% deixaram as argamassas com plasticidade elevada, inviabilizando o assentamento de blocos de concreto. 
Figura 2 - (a) Prismas de 3 blocos (avaliação do desempenho das argamassas à compressão) e (b) miniprismas (avaliação da tensão de aderência bloco/argamassa)

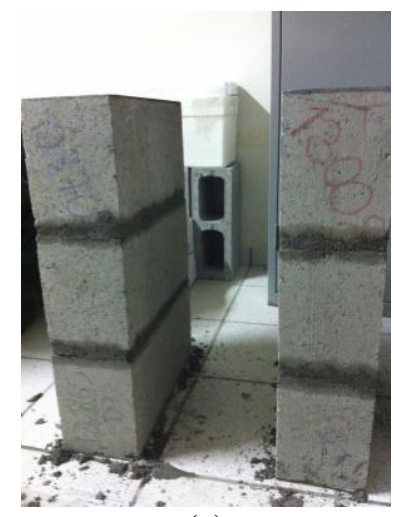

(a)

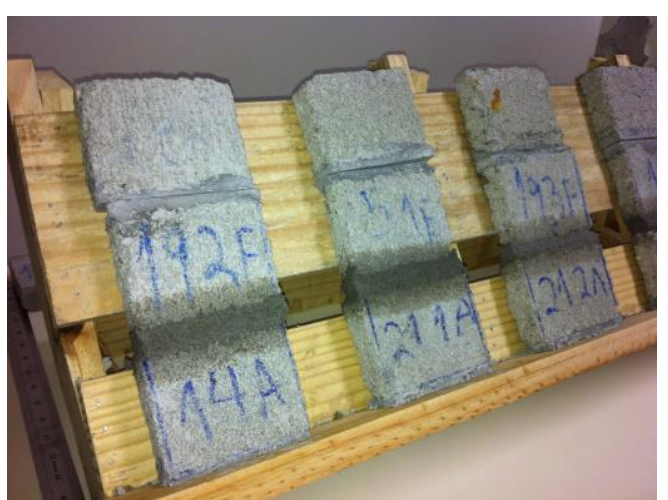

(b)

Figura 3 - Detalhe da obtenção dos pedaços de blocos, confecção dos miniprismas e ensaio de flexão (4 pontos) - dimensões em $\mathrm{mm}$
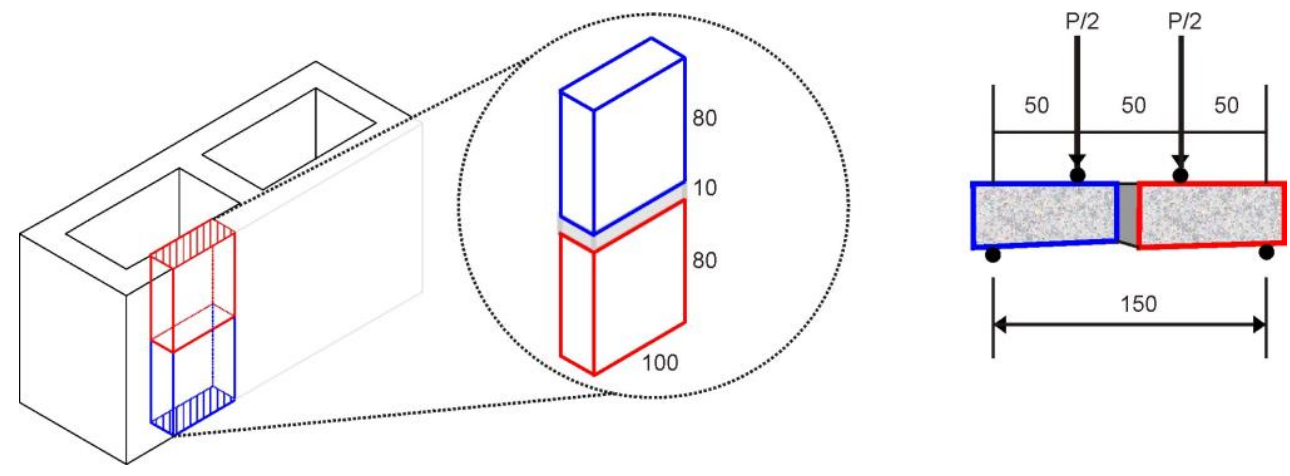

Figura 4 - (a) Detalhe da cravação pneumática de pinos e (b) aparato de fixação dos relógios comparadores para determinação do módulo de deformação de prismas de alvenaria

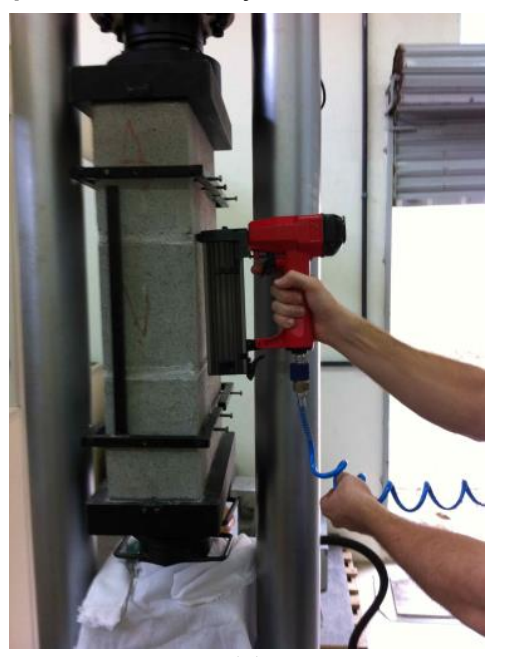

(a)

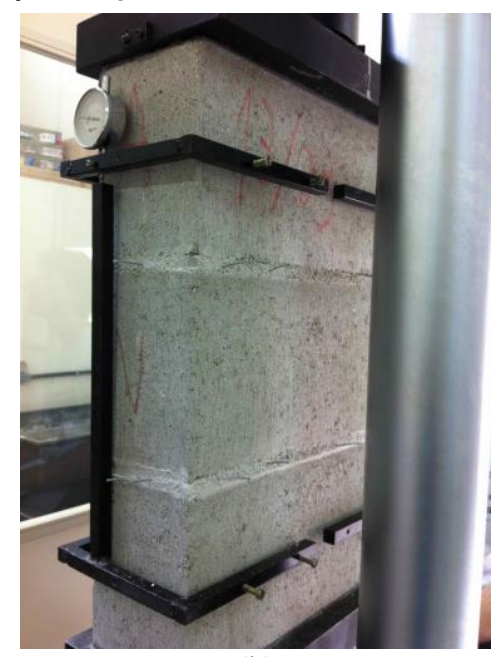

(b)

62 Oliveira, A. L.; Corrêa, B. P.; Ribeiro, I. F. R.; Souza, R. A.; Calçada; L. M. L. 
Ao término dos ensaios de ruptura foram coletados pequenos pedaços de juntas de alvenaria e de corpos de prova cilíndricos $(5 \mathrm{~cm} \times 10 \mathrm{~cm})$ para a determinação da absorção de água por imersão e, por consequência, do índice de vazios dos referidos materiais, seguindo as preconizações da NBR 9778 (ABNT, 2009).

\section{Resultados e discussões}

\section{Fase 1: avaliação da influência do aditivo à base de éter de celulose nas propriedades das argamassas}

Na Tabela 7 são apresentados os resultados de índice de consistência, teor de ar incorporado, retenção de água e resistência à compressão aos 28 dias de idade, para as argamassas confeccionadas na primeira fase do presente estudo.

Com base nos resultados apresentados na Tabela 7 pode-se verificar que a adição do HPMC nas argamassas influenciou sensivelmente o índice de consistência. Essa diferença pode ter sido causada pelo aprisionamento de parte da água de amassamento pelo próprio polímero.

No que tange à retenção de água das argamassas, o emprego do HPMC e o aumento das dosagens do referido polímero aumentaram a capacidade retentiva das argamassas, se comparado com o valor obtido para a argamassa de referência. Quando do emprego do aditivo desincorporador de ar, houve pequena redução na capacidade retentiva de água das argamassas, não sendo possível comprovar se essa diferença foi significativa.

Os resultados de teor de ar incorporado das misturas mostraram que as argamassas confeccionadas com HPMC sofreram incorporações excessivas de ar. Esse efeito pode ter sido o responsável pelas reduções significativas na resistência à compressão aos 28 dias de idade (resultados de resistência das argamassas R-3, R-6, R-9 e REF - $\mathrm{F}_{\text {observado }}>\mathrm{F}_{\text {crítico }}$ - Tabela 8). Com o emprego do aditivo desincorporador, os teores de ar das argamassas (RD-3, RD-6 e RD-9) ficaram muito parecidos com o valor obtido para as argamassas de referência. Fazendo-se um teste de análise de variância entre os resultados de resistência das argamassas RD-3, RD-6, RD-9 e REF, pôde-se verificar que não houve diferenças significativas, com um nível de confiabilidade de 95\% $\left(\mathrm{F}_{\text {observado }}<\mathrm{F}_{\text {crítico }}\right)-$ Tabela 8 .

Em função dos resultados apresentados foram selecionadas as argamassas REF, RD-3, RD-6 e RD-9 para emprego na segunda fase do programa experimental do presente trabalho. Essa escolha se deu pelo fato de as argamassas apresentarem características muito semelhantes no que tange à resistência à compressão e teor de ar incorporado e capacidades retentivas de água bastante distintas.

Tabela 7 - Resultados de índice de consistência, teor de ar incorporado, retenção de água e resistência à compressão aos 28 dias

\begin{tabular}{ccccccc}
\hline \multirow{2}{*}{ Argamassa } & \multirow{2}{*}{$\begin{array}{c}\text { Flow table } \\
(\mathbf{m m})\end{array}$} & $\begin{array}{c}\text { Teor de ar } \\
(\boldsymbol{\%})\end{array}$ & Ret. de & \multicolumn{2}{c}{ Resistência à compressão } \\
\cline { 6 - 7 } & & & água $(\boldsymbol{\%})$ & Média (MPa) & $\begin{array}{c}\text { Sd } \\
(\mathbf{M P a})\end{array}$ & $\mathbf{C V}(\boldsymbol{\%})$ \\
\hline REF & 29,5 & 5,29 & 67,10 & 8,88 & 0,16 & 1,83 \\
R-3 & 23,0 & 10,61 & 86,22 & 6,53 & 0,12 & 1,84 \\
R-6 & 24,0 & 24,33 & 88,95 & 4,24 & 0,20 & 4,74 \\
R-9 & 24,3 & 25,55 & 98,83 & 3,99 & 0,23 & 5,67 \\
RD-3 & 24,0 & 4,74 & 80,84 & 7,47 & 0,34 & 4,58 \\
RD-6 & 22,8 & 5,10 & 85,78 & 7,49 & 0,48 & 6,42 \\
RD-9 & 23,8 & 5,41 & 94,82 & 7,59 & 0,60 & 7,95 \\
\hline
\end{tabular}

Tabela 8 - Resultados da análise estatística (ANOVA) - comparação múltipla de média para fator único

\begin{tabular}{|c|c|c|c|c|c|c|}
\hline & Fonte de variação & $\begin{array}{c}\text { Somatória dos } \\
\text { quadrados dos } \\
\text { desvios }\end{array}$ & $\begin{array}{c}\text { Graus de } \\
\text { liberdade }\end{array}$ & $\begin{array}{c}\text { Médias } \\
\text { quadradas }\end{array}$ & $\mathbf{F}_{\text {observado }}$ & $\mathbf{F}_{\text {crítico }}$ \\
\hline \multirow{3}{*}{ 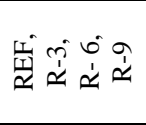 } & Entre grupos & 33,01 & 3,00 & 11,00 & \multirow{3}{*}{11,00} & \multirow{6}{*}{4,07} \\
\hline & Dentro dos grupos & 3,68 & 8,00 & 0,46 & & \\
\hline & Total & 36,69 & 11,00 & & & \\
\hline \multirow{3}{*}{ 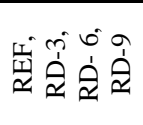 } & Entre grupos & 4,53 & 3 & 1,51 & \multirow{3}{*}{3,46} & \\
\hline & Dentro dos grupos & 3,50 & 8 & 0,44 & & \\
\hline & Total & 8,03 & 11 & & & \\
\hline
\end{tabular}




\section{Fase 2: avaliação do desempenho das argamassas em blocos de concreto}

Na Tabela 9 são apresentados os resultados de resistência à compressão, obtidos para as argamassas mediante o rompimento de corpos de prova cilíndricos $(5 \times 10 \mathrm{~cm})$, bem como a estimativa da resistência à compressão das juntas dos prismas de alvenaria (superior e inferior cravação pneumática de pinos). Conforme mencionado anteriormente, essas estimativas foram realizadas empregando-se a curva de correlação (profundidade de cravação de pinos $\mathrm{x}$ resistência à compressão) proposta por Oliveira et al. (2012) - Figura 5. São apresentados também os resultados de índice de vazios, obtidos para as argamassas empregadas na confecção dos corpos de prova cilíndricos e das juntas de assentamento.

Analisando-se os resultados apresentados na referida tabela, pode-se verificar que houve aumento significativo na resistência à compressão das juntas em relação aos resultados obtidos para os corpos de prova, principalmente para as juntas inferiores. Esse aumento pode ter ocorrido devido à perda de água das juntas para os blocos. Como a relação água/cimento $(\mathrm{a} / \mathrm{c})$ dessas argamassas é muito elevada, eventuais reduções no conteúdo de água das juntas recém-assentadas, juntamente com as cargas dos blocos posicionados em cima, podem ter causado redução na porosidade das juntas.
Pode-se verificar que os valores obtidos nos ensaios de índice de vazios das juntas foram sempre inferiores aos valores obtidos para os corpos de prova cilíndricos $(5 \times 10 \mathrm{~cm})$. No caso das juntas inferiores, esse aumento se tornou mais pronunciado, provavelmente por conta do maior peso aplicado (dois blocos sobre a referida junta).

Quando do emprego do HPMC, as resistências à compressão das juntas de assentamento foram significativamente inferiores (Tabela 10), se comparadas com os valores obtidos para a junta de assentamento confeccionada com a argamassa de referência. Contudo, dentro das argamassas aditivadas com HPMC e desincorporador (RD-3, RD-6, RD-9), os resultados mostraram não haver diferenças significativas (Tabela 11). Acredita-se que essas diferenças na resistência à compressão das juntas de assentamento confeccionadas com as argamassas de referência e argamassas contendo HPMC tenha ocorrido devido à maior retenção de água das argamassas aditivadas, fazendo com que a redução na relação a/c e a maior compactação das juntas de assentamento tenham sido inferiores às da argamassa de referência. Isso pode ser comprovado analisando-se os resultados de índice de vazios, em que as juntas de assentamento (superior e inferior) apresentaram valores mais elevados para as argamassas com HPMC se comparados aos valores obtidos para a argamassa de referência.

Figura 5 - Curva de correlação entre profundidade de cravação de pinos e resistência à compressão empregada na estimativa da resistência à compressão das juntas de assentamento

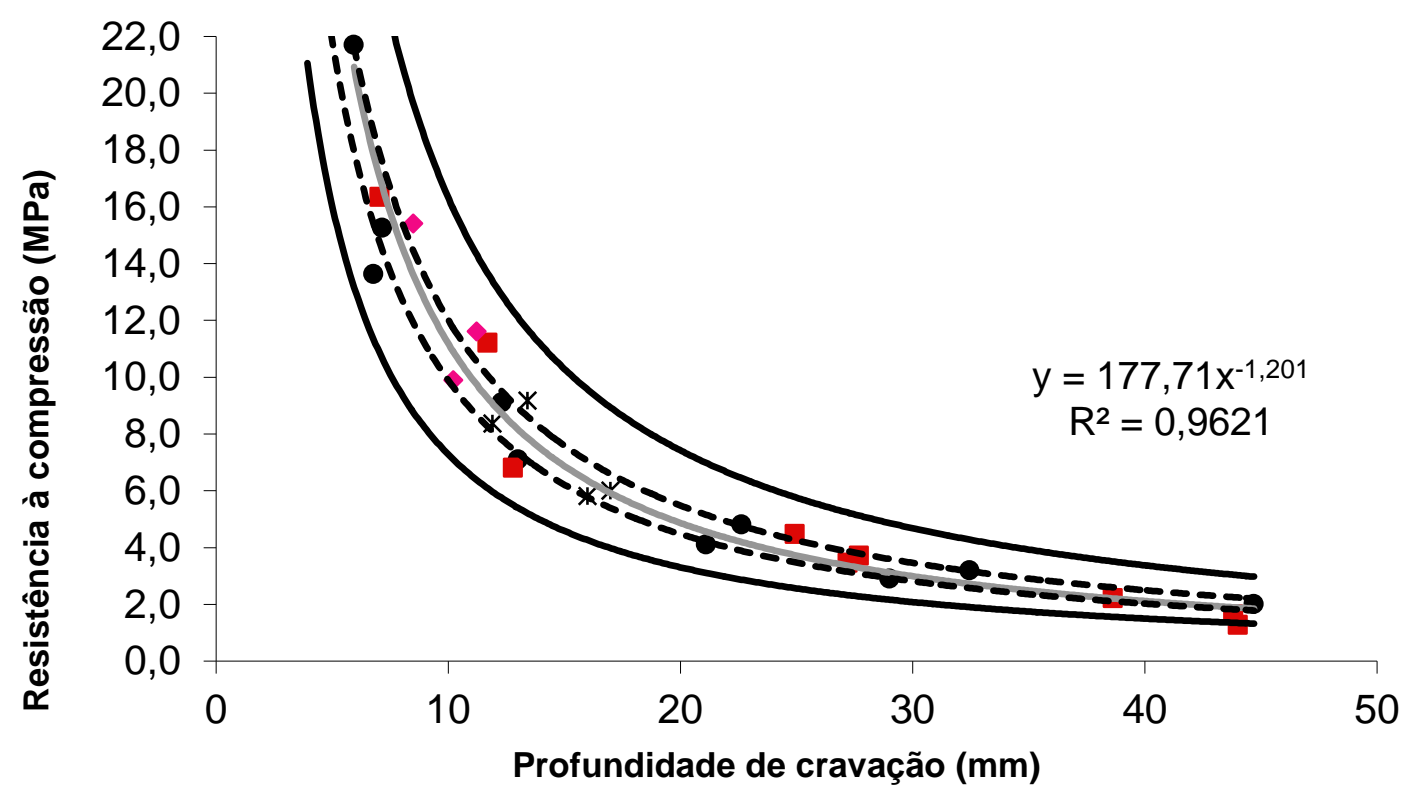

Fonte: Oliveira et al. (2012). 
Tabela 9 - Resistência à compressão e porosidade aberta dos corpos de prova cilíndricos $(5 \times 10 \mathrm{~cm})$ confeccionados na segunda fase do trabalho e das juntas de assentamento

\begin{tabular}{|c|c|c|c|c|c|}
\hline \multicolumn{2}{|c|}{ Argamassa } & \multirow{2}{*}{$\begin{array}{c}\text { Resistência à compressão } \\
\text { média (MPa) }\end{array}$} & \multirow{2}{*}{$\frac{\mathbf{S d}(\mathbf{M P a})}{0,43}$} & \multirow{2}{*}{$\frac{\mathrm{CV}(\boldsymbol{\%})}{6,32}$} & \multirow{2}{*}{$\frac{\text { Índice de } \operatorname{vazios}^{\mathbf{4}}(\boldsymbol{\%})}{15,44}$} \\
\hline \multirow{3}{*}{ REF } & $\mathrm{CP}^{1}$ & & & & \\
\hline & J. $\sup ^{2}$ & 8,95 & 0,94 & 10,50 & 13,84 \\
\hline & J. inf ${ }^{3}$ & 11,43 & 0,91 & 7,92 & 12,88 \\
\hline \multirow{3}{*}{ RD-3 } & $\mathrm{CP}^{1}$ & 6,98 & 0,49 & 7,05 & 16,32 \\
\hline & J. $\sup ^{2}$ & 7,17 & 1,10 & 15,30 & 15,86 \\
\hline & J. inf ${ }^{3}$ & 9,63 & 0,87 & 8,99 & 14,67 \\
\hline \multirow{3}{*}{ RD-6 } & $\mathrm{CP}^{1}$ & 6,93 & 0,34 & 4,95 & 16,77 \\
\hline & J. $\sup ^{2}$ & 7,22 & 1,18 & 11,62 & 14,54 \\
\hline & J. inf ${ }^{3}$ & 8,91 & 0,84 & 7,68 & 14,66 \\
\hline \multirow{3}{*}{ RD-9 } & $\mathrm{CP}^{1}$ & 7,53 & 0,26 & 3,38 & 17,40 \\
\hline & J. $\sup ^{2}$ & 7,52 & 1,05 & 13,92 & 16,46 \\
\hline & J. $\inf ^{3}$ & 9,31 & 1,06 & 11,37 & 13,47 \\
\hline
\end{tabular}

Nota: 1 - CP - Corpos de prova cilíndricos $(5 \times 10 \mathrm{~cm}) ; 2$ - J. sup - Junta superior do prisma de alvenaria (3 blocos); 3 - J. inf - Junta inferior do prisma de alvenaria (3 blocos); e 4 - Relação entre o volume de poros permeáveis e o volume total da amostra.

Tabela 10 - Resultados da análise estatística - ANOVA - experimento fatorial

\begin{tabular}{cccccc}
\hline $\begin{array}{c}\text { Fonte de } \\
\text { variação }\end{array}$ & $\begin{array}{c}\text { Somatória dos quadrados } \\
\text { dos desvios }\end{array}$ & $\begin{array}{c}\text { Graus de } \\
\text { liberdade }\end{array}$ & $\begin{array}{c}\text { Médias } \\
\text { quadradas }\end{array}$ & Fobservado $_{\text {codín }}$ & F $_{\text {críco }}$ \\
\hline Teor de aditivo & 158,08 & 3 & 52,69 & 53,68 & 2,60 \\
Junta & 134,62 & 1 & 134,62 & 137,14 & 3,84 \\
Teor x junta & 14,27 & 3 & 4,76 & 4,84 & 2,60 \\
Resíduo & 135,47 & 138 & 0,98 & & \\
Total & 442,44 & 145 & & & \\
\hline
\end{tabular}

Tabela 11 - Teste de Duncan (avaliação de diferenças significativas - juntas de assentamento)

\begin{tabular}{|c|c|c|c|c|c|}
\hline & Argamassas & Diferenças & Número de grupos & Valor crítico & Resultados \\
\hline \multirow{6}{*}{ 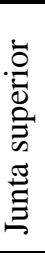 } & RD-3 - RD-6 & 0,05 & 2 & 0,68 & N.D.S \\
\hline & RD-3 - RD-9 & 0,35 & 3 & 0,82 & N.D.S \\
\hline & RD-3 - REF & 1,78 & 4 & 0,90 & D.S. \\
\hline & RD-6 - RD-9 & 0,30 & 2 & 0,68 & N.D.S \\
\hline & RD-6 - REF & 1,73 & 3 & 0,82 & D.S. \\
\hline & RD-9 - REF & 1,43 & 2 & 0,68 & D.S. \\
\hline \multirow{6}{*}{ 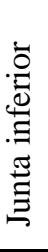 } & RD-6- RD-9 & 0,40 & 2 & 0,68 & N.D.S \\
\hline & RD-6 - RD-3 & 0,72 & 3 & 0,82 & N.D.S \\
\hline & RD-6 - REF & 2,52 & 4 & 0,90 & D.S. \\
\hline & RD-9 - RD-6 & 0,32 & 2 & 0,68 & N.D.S \\
\hline & RD-9 - REF & 2,12 & 3 & 0,82 & D.S. \\
\hline & RD-3 - REF & 1,8 & 2 & 0,68 & D.S. \\
\hline
\end{tabular}

Nota: N.D.S. - Não difere significativamente; e D.S. - Difere significativamente.

Na Tabela 12 são apresentados os resultados de módulo de deformação obtidos mediante os ensaios em corpos de prova cilíndricos, juntamente com os módulos de deformação obtidos para os prismas de alvenaria de 3 blocos. Vale ressaltar que tanto para os ensaios realizados com os corpos de prova cilíndricos como para os prismas de alvenaria foram determinados os módulos secantes resultantes da reta que une os pontos cuja tensão corresponde a $5 \%$ e $33 \%$ da tensão de ruptura, conforme recomendado pela ACI 530/ASCE 5/TMS 402 (AMERICAN..., 1996).

Fazendo-se uma comparação múltipla de médias para fator único (Tabela 13), pode-se verificar que os resultados de módulo de deformação obtidos nos ensaios em corpos de prova cilíndricos não diferem significativamente, com nível de 
confiabilidade de $95 \%\left(\mathrm{~F}_{\text {observado }}<\mathrm{F}_{\text {crítico }}\right)$. O mesmo não aconteceu com os resultados obtidos para os prismas de alvenaria, em que houve diferenças significativas, com grau de confiabilidade de $95 \%\left(\mathrm{~F}_{\text {observado }}>\mathrm{F}_{\text {crítico }}\right.$ - Tabela 14). O valor do módulo de deformação dos prismas confeccionados com a argamassa de referência foi significativamente superior aos demais prismas confeccionados com as argamassas contendo HPMC (Tabela 15). De forma semelhante ao que ocorreu com as resistências à compressão das juntas, acredita-se que as argamassas contendo HPMC tenham perdido menos água para os blocos se comparadas à argamassa de referência; com isso, as juntas de assentamento da argamassa de referência apresentaram maior compacidade e, consequentemente, maior resistência à compressão, tornando o prisma de alvenaria menos deformável. Entre as argamassas aditivadas (RD-3, RD-6 e RD-9), os prismas confeccionados com a argamassa com 0,09\% de HPMC apresentaram valores de módulo de deformação inferiores significativamente se comparados aos resultados obtidos para as argamassas com $0,03 \%$ e $0,06 \%$ (Tabela 15). Vale ressaltar que a argamassas RD-9 foi a que apresentou o maior poder de retenção de água entre as argamassas testadas.
$\mathrm{Na}$ Tabela 16 são apresentados os resultados de resistência à compressão e os respectivos fatores de eficiência obtidos para os prismas de alvenaria com as diferentes argamassas empregadas. Os resultados obtidos no presente estudo mostraram que as resistências à compressão dos prismas de alvenaria não apresentaram diferenças significativas (Tabela 17), com grau de confiabilidade de $95 \%\left(\mathrm{~F}_{\text {observado }}<\mathrm{F}_{\text {crítico }}\right)$.

Já para os resultados de tensão de aderência obtida na flexão dos miniprismas (Tabela 18), o que se percebeu foi que o emprego do HPMC causou redução significativa na referida propriedade (Tabela 19 e 20), com grau de confiabilidade de 95\%. Contudo, com o aumento do teor de HPMC não houve diferença significativa na tensão de aderência dos miniprismas (Tabela 20).

De acordo com Holzer, Jenni e Zurbriggen (2001), os polímeros à base de éter de celulose podem se solubilizar e se deslocar enquanto existe a presença de água. Com isso, pode ter havido migração do HPMC por conta da sucção dos blocos para a zona de interface (bloco/argamassa) ainda no estado plástico das argamassas, formando um filme (película); esse filme pode ter contribuído para reduzir a tensão de aderência das argamassas aditivadas.

Tabela 12 - Resultados de módulo de deformação dos corpos de prova cilíndricos e dos prismas de alvenaria (3 blocos)

\begin{tabular}{|c|c|c|c|c|}
\hline & Argamassas & $E(G P a)^{2}$ & Sd (GPa) & $\mathrm{CV}(\%)$ \\
\hline \multirow{4}{*}{$\overline{0}$} & REF & 6,43 & 0,75 & 11,67 \\
\hline & RD-3 & 6,60 & 1,04 & 15,75 \\
\hline & RD-6 & 5,73 & 0,31 & 5,33 \\
\hline & RD-9 & 6,17 & 0,47 & 7,66 \\
\hline \multirow{4}{*}{ 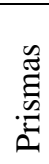 } & REF & 13,39 & 1,26 & 9,43 \\
\hline & RD-3 & 7,51 & 0,26 & 3,52 \\
\hline & RD-6 & 8,08 & 0,57 & 7,08 \\
\hline & RD-9 & 5,89 & 0,33 & 5,59 \\
\hline
\end{tabular}

Nota: 1 - Corpos de prova cilíndricos $(5 \times 10 \mathrm{~cm})$; e 2 - Módulo de deformação médio.

Tabela 13 - Resultados da análise estatística (ANOVA) - comparação múltipla de média para fator único (módulo de deformação - corpos de prova cilíndricos)

\begin{tabular}{c|c|c|c|c|c}
\hline Fonte de variação & $\begin{array}{c}\text { Somatória dos } \\
\text { quadrados dos desvios }\end{array}$ & $\begin{array}{c}\text { Graus de } \\
\text { liberdade }\end{array}$ & $\begin{array}{c}\text { Médias } \\
\text { quadradas }\end{array}$ & \multirow{2}{*}{$\mathbf{F}_{\text {observado }}$} & \multirow{2}{*}{ F $_{\text {crítico }}$} \\
\hline Entre grupos & 1,29 & 3,00 & 0,43 & \multirow{2}{*}{0,88} & \multirow{2}{*}{4,07} \\
\cline { 1 - 4 } Dentro dos grupos & 3,92 & 8,00 & 0,49 & & \\
\hline Total & 5,21 & 11,00 & & & \\
\hline
\end{tabular}

66 Oliveira, A. L.; Corrêa, B. P.; Ribeiro, I. F. R.; Souza, R. A.; Calçada; L. M. L. 
Tabela 14 - Resultados da análise estatística (ANOVA) - comparação múltipla de média para fator único (módulo de deformação - prismas)

\begin{tabular}{c|c|c|c|c|c}
\hline $\begin{array}{c}\text { Fonte de } \\
\text { variação }\end{array}$ & $\begin{array}{c}\text { Somatória dos } \\
\text { quadrados dos desvios }\end{array}$ & $\begin{array}{c}\text { Graus de } \\
\text { liberdade }\end{array}$ & $\begin{array}{c}\text { Médias } \\
\text { quadradas }\end{array}$ & F $_{\text {observado }}$ & \multirow{2}{*}{ F $_{\text {crítico }}$} \\
\hline Entre grupos & 63,49 & 3,00 & 21,16 & \multirow{2}{*}{40,33} & \multirow{2}{*}{6,59} \\
\hline Dentro dos grupos & 2,10 & 4,00 & 0,52 & & \\
\hline Total & 65,59 & 7,00 & & & \\
\hline
\end{tabular}

Tabela 15 - Teste de Duncan (avaliação de diferenças significativas - módulo de deformação dos prismas)

\begin{tabular}{c|c|c|c|c}
\hline Argamassas & Diferenças & $\begin{array}{c}\text { Número de } \\
\text { grupos }\end{array}$ & Valor crítico & Resultados \\
\hline RD-3 - RD-6 & 0,57 & 2 & 1,45 & N.D.S \\
\hline RD-3 - RD-9 & 1,62 & 2 & 1,45 & D.S \\
\hline RD-3 - REF & 5,88 & 3 & 1,74 & D.S. \\
\hline RD-6 - RD-9 & 2,19 & 3 & 1,74 & D.S \\
\hline RD-6 - REF & 5,31 & 2 & 1,45 & D.S. \\
\hline RD-9 - REF & 7,51 & 4 & 1,92 & D.S. \\
\hline
\end{tabular}

Nota: N.D.S. - Não difere significativamente; e D.S. - Difere significativamente.

Tabela 16 - Resistência à compressão e fatores de eficiência dos prismas de alvenaria

\begin{tabular}{c|c|c|c|c}
\hline Argamassas & $\begin{array}{c}\text { Resistência à compressão } \\
\text { média (MPa) }\end{array}$ & Sd (MPa) & CV (\%) & $\begin{array}{c}\text { Fator de } \\
\text { eficiência }^{\mathbf{1}}\end{array}$ \\
\hline REF & 5,26 & 0,36 & 6,88 & 62,81 \\
\hline RD-3 & 6,14 & 0,25 & 4,00 & 73,23 \\
\hline RD-6 & 5,60 & 0,61 & 10,80 & 66,87 \\
\hline RD-9 & 5,61 & 0,29 & 5,10 & 66,95 \\
\hline
\end{tabular}

Nota: Fator de eficiência = resistência à compressão média dos prismas dividida pela resistência à compressão média dos blocos $(8,38 \mathrm{MPa})$.

Tabela 17 - Resultados da análise estatística (ANOVA) - comparação múltipla de média para fator único (resistência à compressão - prismas)

\begin{tabular}{c|c|c|c|c|c}
\hline $\begin{array}{c}\text { Fonte de } \\
\text { variação }\end{array}$ & $\begin{array}{c}\text { Somatória dos } \\
\text { quadrados dos desvios }\end{array}$ & $\begin{array}{c}\text { Graus de } \\
\text { liberdade }\end{array}$ & $\begin{array}{c}\text { Médias } \\
\text { quadradas }\end{array}$ & F $_{\text {observado }}$ & \multirow{2}{*}{ F $_{\text {crítico }}$} \\
\hline Entre grupos & 1,17 & 3,00 & 0,39 & \multirow{2}{*}{2,44} & \multirow{2}{*}{4,07} \\
\cline { 1 - 4 } Dentro dos grupos & 1,28 & 8,00 & 0,16 & & \\
\hline Total & 2,45 & 11,00 & & \\
\hline
\end{tabular}

Tabela 18 - Tensões de aderência obtidas no ensaio de flexão em miniprismas

\begin{tabular}{c|c|c|c}
\hline Argamassas & $\begin{array}{c}\text { Tensão de aderência } \\
\text { média (MPa) }\end{array}$ & Sd (MPa) & CV (\%) \\
\hline REF & 0,67 & 0,12 & 18,40 \\
RD-3 & 0,12 & 0,01 & 4,68 \\
RD-6 & 0,24 & 0,06 & 26,38 \\
RD-9 & 0,20 & 0,05 & 26,70 \\
\hline
\end{tabular}


Tabela 19 - Resultados da análise estatística (ANOVA) - comparação múltipla de média para fator único (tensão de aderência - miniprismas)

\begin{tabular}{c|c|c|c|c|c}
\hline Fonte de variação & $\begin{array}{c}\text { Somatória dos } \\
\text { quadrados dos desvios }\end{array}$ & $\begin{array}{c}\text { Graus de } \\
\text { liberdade }\end{array}$ & $\begin{array}{c}\text { Médias } \\
\text { quadradas }\end{array}$ & \multirow{2}{*}{$\mathbf{F}_{\text {observado }}$} & \multirow{2}{*}{ F $_{\text {crítico }}$} \\
\hline Entre grupos & 0,89 & 3,00 & 0,30 & \multirow{2}{*}{36,71} & \multirow{2}{*}{5,18} \\
\cline { 1 - 4 } Dentro dos grupos & 0,14 & 17,00 & 0,01 & & \\
\hline Total & 1,03 & 20,00 & & & \\
\hline
\end{tabular}

Tabela 20 - Teste de Duncan (avaliação de diferenças significativas - tensão de aderência em miniprismas)

\begin{tabular}{c|c|c|c|c}
\hline Argamassas & Diferenças & Número de grupos & Valor crítico & Resultados \\
\hline RD-3 - RD-6 & 0,12 & 3 & 0,14 & N.D.S \\
RD-3 - RD-9 & 0,07 & 2 & 0,11 & N.D.S \\
RD-3 - REF & 0,55 & 4 & 0,15 & D.S. \\
RD-6 - RD-9 & 0,05 & 2 & 0,11 & N.D.S \\
RD-6 - REF & 0,43 & 2 & 0,11 & D.S. \\
RD-9 - REF & 0,48 & 3 & 0,14 & D.S. \\
\hline
\end{tabular}

Nota: D.S. - Não difere significativamente; e D.S. - Difere significativamente.

\section{Conclusões}

Com base nos resultados apresentados no presente trabalho pode-se verificar que:

(a) o HPMC aumentou a capacidade de retenção de água das argamassas; contudo causou incorporação excessiva de ar nelas. Esse efeito secundário de incorporação de ar pode ser controlado com o emprego de um aditivo desincorporador de ar, quando em teores próximos de 2,0\% em relação à massa de cimento;

(b) o HPMC não afetou os valores de resistência à compressão das argamassas quando determinados mediante o rompimento de corpos de prova cilíndricos $(5 \times 10 \mathrm{~cm})$. Porém, as resistências à compressão das juntas de assentamento, medidas por ensaio de cravação pneumática de pinos, sofreram reduções significativas se comparadas às juntas de assentamento produzidas com a argamassa de referência. Esse fato pode ter sido ocasionado pela maior retentividade das argamassas confeccionadas com o HPMC. Com isso, as juntas de assentamento de referência perderam mais água, resultando em uma menor relação a/c e em maior compacidade, haja vista os menores valores de índice de vazios;

(c) os prismas de alvenaria não sofreram variações significativas na resistência à compressão e no fator de eficiência com o emprego do HPMC. Contudo, o emprego do HPMC resultou em prismas mais deformáveis (menor módulo de deformação). Esse fato deve ser levado em consideração, pois alvenarias mais deformáveis, sem prejuízo na capacidade portante, podem ser de grande utilidade na redução de problemas patológicos devido a deformações impostas por movimentações térmicas, estruturais, recalques de fundações, etc.; e

(d) o emprego do HPMC resultou em redução significativa nas tensões de aderência das argamassas, determinadas mediante ensaio de flexão em quatro pontos, independente do teor de HPMC empregado $(0,03 \%, 0,06 \%$ e $0,09 \%$ em relação à massa total de material seco).

\section{Referências}

AFRIDI, M. U. K. et al. Water Retention and Adhesion of Powdered and Aqueous PolymerModified Mortars. Cement and Concrete Composites, v. 17, n. 4, p. 113-118, 1995.

AMERICAN SOCIETY FOR TESTING AND MATERIALS. Standard C91 section 7.2 and 7.3: specification for masonry cement: determination of water retention and air content. West Conshohocken, 2003.

AMERICAN CONCRETE INSTITUTE; AMERICAN SOCIETY OF CIVIL ENGINEERS; THE MASONRY SOCIETY. Building Code Requirements for Masonry Structures. Detroit, 1996. ACI 530/ASCE 5/TMS 402,

ASSOCIAÇÃO BRASILEIRA DE NORMAS TÉCNICAS. NBR-6136: blocos vazados de concreto simples para alvenaria: requisitos. Rio de Janeiro, 2007.

ASSOCIAÇÃO BRASILEIRA DE NORMAS

TÉCNICAS. NBR 9778: argamassa e concreto endurecidos: determinação da absorção de água, índice de vazios e massa específica. Rio de Janeiro, 2009. 


\section{ASSOCIAÇÃO BRASILEIRA DE NORMAS}

TÉCNICAS. NBR-13276: argamassa para assentamento e revestimento de paredes e tetos: preparo da mistura e determinação do índice de consistência. Rio de Janeiro, 2005a.

\section{ASSOCIAÇÃO BRASILEIRA DE NORMAS} TÉCNICAS. NBR 13278: argamassa para assentamento e revestimento de paredes e tetos: determinação da densidade de massa e do teor de ar incorporado. Rio de Janeiro, 2005b.

\section{CASALI, J. M. Estudo da Interação Entre a}

Argamassa de Assentamento e o Bloco de Concreto Para Alvenaria Estrutural: transporte de água e aderência. Florianópolis, 2008. Tese (Doutorado em Engenharia Civil) - Escola de Engenharia, Universidade Federal de Santa Catarina, Florianópolis, 2008.

HOLZER, L.; JENNI, A.; ZURBRIGGEN, R. Eine in-situ ESEM: studie qber mikrostrukturelle Veränderungen polymervergqteter Mörtel während der Wasserlagerung. In:TAGUNG BAUCHEMIE, 3., Frankfurt, 2001. Proceedings... Frankfurt, 2001.

JENNI, A. et al. Influence of Polymers on Microstructure and Adhesive Strength of Cementitious tile Adhesive Mortars. Cement and Concrete Research, v. 35, n. 1, p. 35-50, 2005.

JENNI, A. el at. Changes in Microstructures and Physical Properties of Polymer-Modified Mortars During Wet Storage. Cement and Concrete Research, v. 36, n. 1, p. 79-90, 2006.
KNAPEN, E.; GEMERT, D. Van. Cement Hydration and Microstructure Formation in the Presence of Water-Soluble Polymers. Cement and Concrete Research, v. 39, n. 1, p. 6-13, 2009.

OLIVEIRA, A. L. et al. Ensaio de Cravação Pneumática de Pino Para Avaliação da Resistência à Compressão de Juntas de Assentamento de Alvenaria Estrutural. Ambiente Construído, Porto Alegre, v. 12, n. 2, p. 175-188, 2012.

PAIVA, H. et al. Effects of a Water-Retaining Agent on the Rheological Behaviour of a SingleCoat Render Mortar. Cement and Concrete Research, v. 36, n. 7, p. 1257-1262, 2006.

PAIVA, H. et al. Rheology and Hardened Properties of Single-Coat Render Mortars With Different Types of Water Retaining Agentes. Construction and Building Materials, v. 23, n. 2, p. 1141-1146, 2009.

STEIL, R. O. Efeito da Geometria do Bloco de Concreto e do Tipo de Argamassa no Desempenho à Compressão de Prisma de Alvenaria Não Grauteados. Florianópolis, 2003. Dissertação (Mestrado em Engenharia Civil) Escola de Engenharia, Universidade Federal de Santa Catarina, Florianópolis, 2003.

SCHANKOSKI, R. A. Influência do Tipo Argamassa nas Propriedades Mecânicas de Alvenarias Estruturais de Blocos de Concreto Para Edifícios Altos. Florianópolis, 2012. Dissertação (Mestrado em Engenharia Civil) Escola de Engenharia, Universidade Federal de Santa Catarina, Florianópolis, 2012.

\footnotetext{
Alexandre Lima Oliveira

Departamento Académico de Construção Civil | Instituto Federal de Santa Catarina | Av. Mauro Ramos, 950, Centro | Florianópolis - SC Brasil | CEP 88020-300 | Tel.: (48) 3221-0560 | E-mail: alexandre@ifsc.edu.br

Bruna Petter Corrêa Schveper

Departamento Académico de Construção Civi | Instituto Federal de Santa Catarina | E-mail: brunapetter@gmail.com

Igor Fernando Reitz Ribeiro

Departamento Académico de Construção Civil | Instituto Federal de Santa Catarina | E-mail: guigoreitz@hotmail.com

Rafael Andrade Souza

Departamento Académico de Construção Civil | Instituto Federal de Santa Catarina | E-mail: ras@ifsc.edu.br

Luciana Maltes Lengler Calçada

Departamento Académico de Construção Civil | Instituto Federal de Santa Catarina | E-mail: lucianamaltez@ifsc.edu.br
}

Revista Ambiente Construído

Associação Nacional de Tecnologia do Ambiente Construído

Av. Osvaldo Aranha, $99-3^{\circ}$ andar, Centro

Porto Alegre - RS - Brasil

CEP 90035-190

Telefone: +55 (51) 3308-4084

Fax: +55 (51) 3308-4054

www.seer.ufrgs.br/ambienteconstruido

E-mail: ambienteconstruido@ufrgs.br 